\title{
Silver Azide Nanoparticles Embedded into Silica as Energetic Nano-materials
}

\author{
Corneliu GHICA ${ }^{1}$, Raluca DAMIAN ${ }^{1}$, Daniela CULITA $^{2}$, Ioana TURCU ${ }^{3}$, Petre IONITA ${ }^{2,} 3^{\text {* }}$ \\ ${ }^{1}$ National Institute for Materials Physics, P.O. Box MG-7, 077125 Bucharest-Magurele, Romania \\ ${ }^{2}$ Institute of Physical Chemistry, 202 Spl. Independentei, Bucharest 060021, Romania \\ ${ }^{3}$ University of Bucharest, Department of Organic Chemistry, Biochemistry and Catalysis, 90-92 Panduri, Bucharest \\ 050663, Romania.
}

cross ref http://dx.doi.org/10.5755/j01.ms.21.3.6926

Received 12 April 2014; accepted 08 November 2014

\begin{abstract}
Silver azide is a primary high explosive that can be initiated by different means. In this work, silver azide nanoparticles were obtained, embedded into silica, and further derivatized with biotin. TEM, DLS, and IR measurements were used to characterize the hybrid energetic nanoparticles. The hybrid nanoparticles are made from an explosive core (silver azide) and a shell (silica), to which has been attached through an organic linker a biological target vectot (biotin). These hybrid nanoparticles can be used as models to study smart energetic nano-materials

Keywords: silver azide; silica; nanoparticles; biotin.
\end{abstract}

\section{INTRODUCTION}

Silver azide is a simple chemical that can be used as a vigorous primary explosive (initiating the explosion of more stable compounds). The explosion of this energetic material can be triggered by heat, impact, friction, or even ultraviolet light [1].

Inspired by the literature data that showed the use of single carbon nanotubes as 'smart bombs' in a photoacoustic therapy procedure that targets cancer cells [2-4], we have developed a different system that can fulfill a similar function. Briefly, the idea was to use silver azide nanoparticles (the energetic material) in conjunction with a target vector, such as biotin. Biotin (also known as vitamin $\mathrm{H}, \mathrm{B}_{7}$, or coenzyme R) can bind very strongly to avidintype proteins with a high degree of affinity and specificity $[5,6]$.

Information in the literature regarding silver azide nanoparticles is extremely scarce. Silver azide $\left(\mathrm{AgN}_{3}\right)$ has been used to obtain silver nanoparticles (Ag NPs) by a solvo-thermal decomposition [7]. Conversely, there is a tremendous amount of data on biotinylation, the procedure in which biotin is covalently attached to a protein or any other molecule [8-10].

Our model of smart energetic material consists of an explosive core of $\mathrm{AgN}_{3} \mathrm{NPs}$, embedded into silica containing free amino groups, to which biotin was covalently attached (Fig. 1).

\section{EXPERIMENTAL}

All chemicals and solvent were supplied by SigmaAldrich. TEM picture were recorded with a Jeol 200CX microscope operated at $200 \mathrm{kV}$, with a carbon copper grid on which a drop of the diluted nanoparticles solution was deposited and allowed to dry at room temperature. DLS measurements were made using a Beckman-Coulter Delsa

\footnotetext{
${ }^{*}$ Corresponding author. Tel.: +40748438735; fax: +40213121147.

E-mail address: pionita@icf.ro (P. Ionita)
}

Nano C Submicron Particle Size Analyzer for the hydrodynamic diameter measurement. The scattered light was measured at $165^{\circ}$ from the incident beam. The CONTIN method was used to resolve particle size distributions.

Caution! Silver azide is a very powerful and hazardous material. Do not synthesize large quantities. Impact, friction, static electricity, temperature, and pressure may induce the detonation. A special awareness must be taken on the proper and safe storage and disposal.

Synthesis of $\mathrm{AgN}_{3} \mathrm{NPs}$. Typical procedure uses two equal volumes of solvent (water, methanol or watermethanol mixture, between $10-50 \mathrm{~mL}$ ), one containing 17 mg of silver nitrate and the other one containing $6.5 \mathrm{mg}$ sodium azide. The two solutions are mixed under stirring, and after $5 \mathrm{~min}$ decantated and used further. For the synthesis of PVP protected $\mathrm{AgN}_{3} \mathrm{NPs}$, the mixture contained $40 \mathrm{mg}$ PVP.

Coverage of $\mathrm{AgN}_{3} \mathrm{NPs}$ with silica. To the previous solution of $\mathrm{AgN}_{3}$ NPs was added under stirring $0.02 \mathrm{~mL} 3-$ aminopropyl-trimethoxysilane and $0.03 \mathrm{~mL}$ tetramethylorthosilicate, and the mixture stirred for about $1 \mathrm{~h}$.

Labeling of hybrid NPs with biotin. Solid hybrid NPs were obtained by centrifugation, washed several times with methanol, then with DCM, and dried. The resulting solid was suspended into DCM, to which biotin (25 mg) and EEDQ (20 mg) were added, and the mixture stirred over night. The next day the solution was centrifuged, and the solid washed for about 10 times with methanol, until no trace of organic compound can be found in methanol.

\section{RESULTS AND DISCUSSION}

To achieve our goal, we first obtained the required $\mathrm{AgN}_{3}$ NPs starting from silver nitrate and sodium azide. Several parameters (the concentration of the reactants, solvent, and the presence (or absence) of polyvinylpyrrolidone (PVP) as a stabilizing ligand) were varied, and the change in the size and shape of the resulting $\mathrm{AgN}_{3} \mathrm{NPs}$ was observed. 
First, it was found that the concentrations of the starting materials (silver nitrate and sodium azide) must be carefully chosen to obtain a good colloidal solution of $\mathrm{AgN}_{3} \quad \mathrm{NPs}$ (higher concentrations led to higher agglomeration, while lower concentration might lead to dissolution of the $\mathrm{AgN}_{3}$ NPs in the next synthesis step).

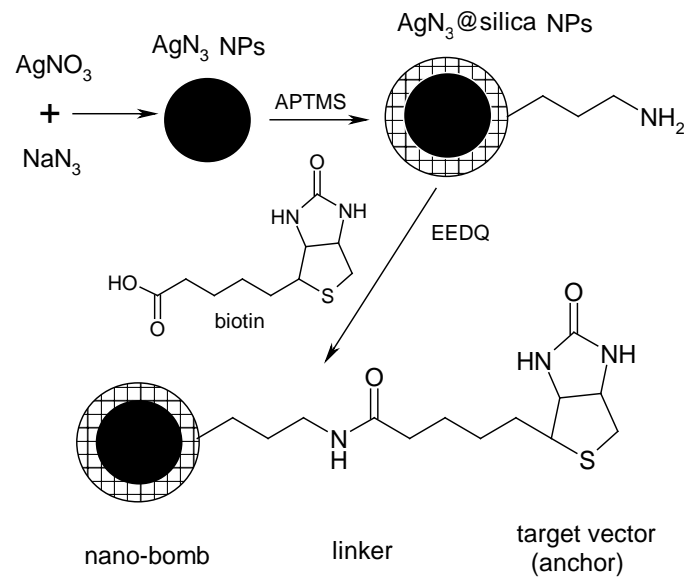

Fig. 1. Synthetic procedure of a smart energetic nano-material

For the solvent, water and methanol were used, as well as their $1 / 1$ mixture. It was noticed that in pure methanol, most of the silver azide precipitates, although some $\mathrm{AgN}_{3}$ NPs can be found in the solution (see supplementary data S1). However, in water or in the water-methanol mixture, $\mathrm{AgN}_{3}$ NPs are formed in good yields. Their size varies from 50 to $500 \mathrm{~nm}$, and they show a wide size distribution. In the end, the synthesis in water was chosen, as it seems to be the most appropriate for the final purpose.

Regarding the use of a stabilizing ligand, it was noticed that the $\mathrm{AgN}_{3} \mathrm{NPs}$ that were synthesized in the presence of PVP formed a more stable suspension, with a narrower size distribution. Fig. 2 a shows the $\mathrm{AgN}_{3}$ NPs obtained in the absence of PVP, while Fig. $2 \mathrm{~b}$ shows the $\mathrm{AgN}_{3}$ NPs obtained in the presence of PVP. The results are unsurprising, as PVP is known to be a good stabilizing ligand for the synthesis of NPs [11, 12].

However, our previous experience and the available literature [13] showed that PVP-protected Ag NPs are difficult to be embedded into a silica layer. This is due to the protective layer of ligand (PVP) that prevents good contact between the metal surface and the silica precursor, eventually leading to a mixture of free Ag NPs and covered ones.

To obtain a full coverage (although not necessary) of $\mathrm{AgN}_{3}$ NPs with silica, many experiments were performed, varying the concentration of the reactants, the duration of the reaction, and the solvent. Fig. 2 c shows the TEM image obtained for plain $\mathrm{AgN}_{3} \mathrm{NPs}$ covered with aminopropylsilica, while Fig. $2 \mathrm{~d}$ shows the TEM image obtained for the $\mathrm{AgN}_{3}$ NPs synthesized in the presence of PVP and covered with aminopropylsilica. It can be seen that in the first case, all of the $\mathrm{AgN}_{3} \mathrm{NPs}_{\text {are covered with }}$ silica, while in the second case, the silica NPs may embed more than one Ag NP. For the $\mathrm{AgN}_{3}$ NPs obtained either in a mixture of methanol-water or in the presence of PVP, the coverage procedure usually affords a mixture of free and embedded NPs (for details see Fig. $3 \mathrm{a}-\mathrm{c}$ ); when using low concentrations of $\mathrm{AgN}_{3} \mathrm{NPs}$, only silica NPs are observed (Fig. 3 d).

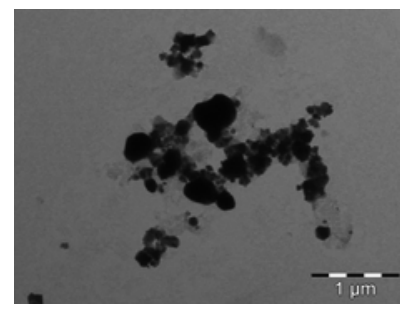

$\mathrm{a}$

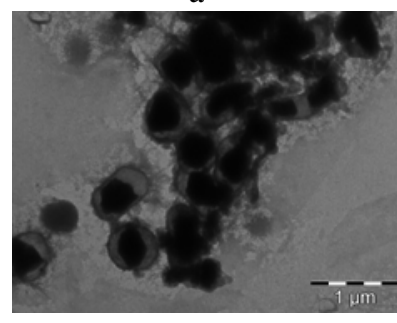

C

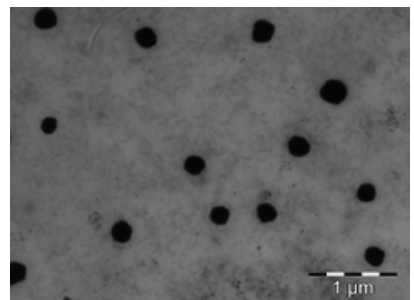

b

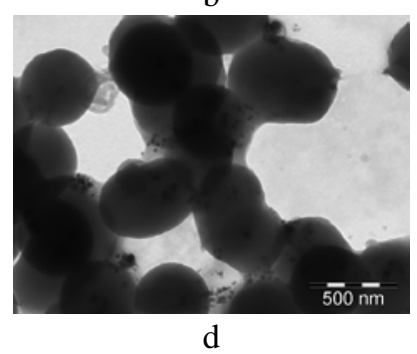

Fig. 2. TEM pictures of $\mathrm{AgN}_{3}$ NPs obtained in the absence (a) and presence (b) of PVP; (c) and (d) are the corresponding hybrid NPs (covered with silica)

DLS analysis can provide similar information as TEM, regarding the mean size and size distribution [14]. Our experiments showed that there is a difference in the size of the hybrid nanoparticles ( $\mathrm{AgN}_{3} @$ silica) between those extracted from the TEM pictures and those obtained from the DLS analysis (see supplementary data S2). This result can be explained through the two different techniques employed; a TEM picture always shows a limited sample of all of the NPs, while the DLS measurements acquire data for all of the NPs based on the hydrodynamic size, which is usually larger than the actual size.
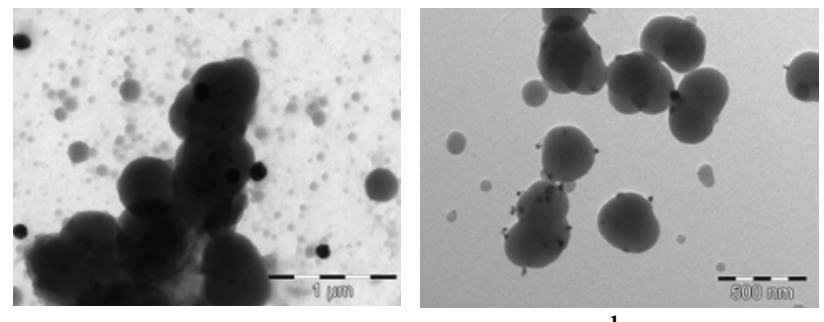

b

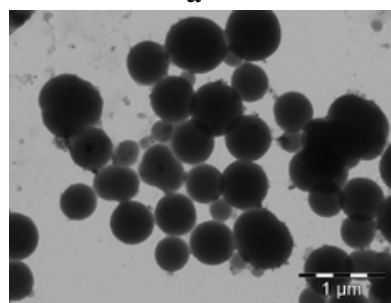

C

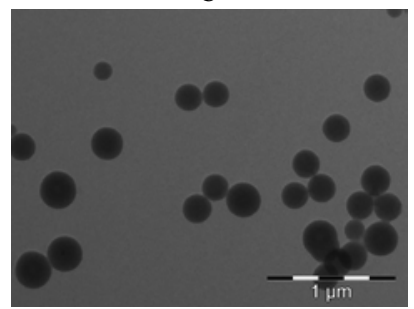

d
Fig. 3. TEM picture obtained in the attempts to embed $\mathrm{AgN}_{3} \mathrm{NPs}$ into silica: a - for PVP protected $\mathrm{AgN}_{3} \mathrm{NPs}$; b-for $\mathrm{AgN}_{3}$ NPs obtained in water-methanol; c-for PVP protected $\mathrm{AgN}_{3} \mathrm{NPs}$ obtained in water-methanol; $\mathrm{d}-$ for $\mathrm{AgN}_{3} \mathrm{NPs}$ obtained in methanol

Moreover, with respect to the TEM measurements, some reports have shown that the electron-beam might induce decomposition of the $\mathrm{AgN}_{3}$ NPs [15]; this phenomenon is observed in our TEM images using energy 


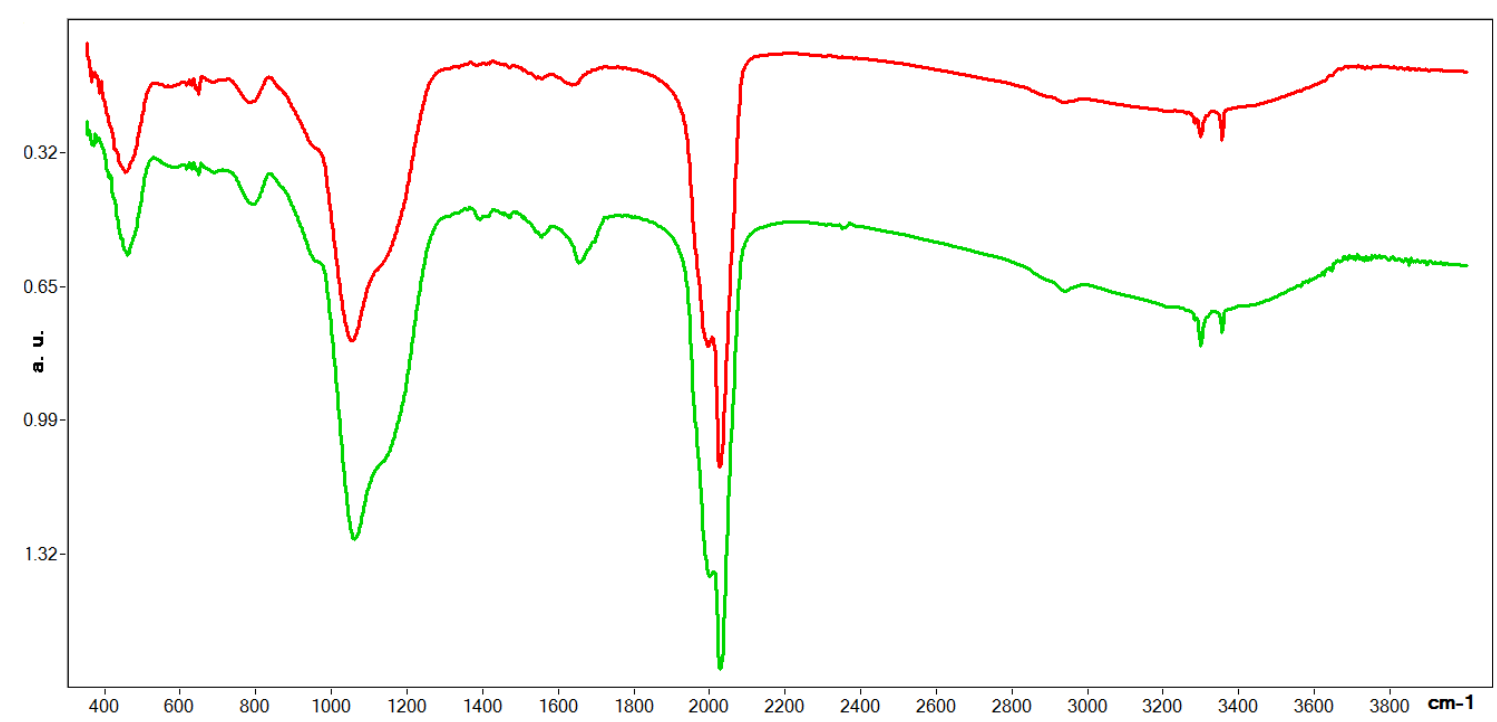

Fig. 4. IR spectra of the hybrid AgN $\mathrm{A}_{3} @$ silica NPs (red) and the hybrid biotin-derivatized AgN $3 @$ silica NPs (green)

dispersive spectroscopy (EDS), which showed that the sample contained more silver than expected (see supplementary data S3).

The last step of the synthetic route was to covalently bond biotin to the hybrid NPs (as shown in Fig. 1). Biotin cannot be directly attached to $\mathrm{AgN}_{3} \mathrm{NPs}$; therefore, the next step in our procedure was to cover these nanoparticles with a layer of silica, specifically aminopropylsilica, which contains free amino groups (as shown in Fig. 1). These free amino groups easily react with carboxylic acids with the aid of a coupling agent such as dicyclohexylcarbodiimide (DCC) or 2-ethoxy-1-ethoxycarbonyl-1,2-dihydroquinoline (EEDQ) [12]. EEDQ was used, due to our previous success with this coupling agent compared with DCC [16]. Fig. 4 shows the recorded IR spectrum of the AgN $3 @$ silica NPs (red), superimposed with the IR spectrum of the hybrid NPs functionalized with biotin (green).

Although the spectra look very similar ( $\mathrm{Si}-\mathrm{O}-\mathrm{Si},-\mathrm{N}_{3}$, $\mathrm{CH}_{2^{-}}$, and $\mathrm{Si}-\mathrm{OH}$ groups appear at approximately 1050 , 2030, 2930, and $3300 \mathrm{~cm}^{-1}$ ), a more intense band corresponding to the newly formed amide (-CO-NH-) groups can be seen at $1650 \mathrm{~cm}^{-1}$.

Regarding the known behavior of $\mathrm{AgN}_{3}$, literature data showed that the explosion temperature can reach $3500 \mathrm{~K}$ [17], and the mechanism of decomposition is quite complicated, following a peculiar kinetics [18].

However, $\mathrm{AgN}_{3}$ can be regarded as an unstable material, as day light can induce decomposition; as well, heat works in the same manner, and if these processes are controlled, the results of decomposition can be silver nanoparticles [7]. It was also shown that the thermal decomposition starts at 523K, the initial mechanistic step being the scission of a N-N bond [19].

Our simple heating tests on the $\mathrm{AgN}_{3}$ NPs showed that whether they were embedded in the silica layer or not, or further derivatized with biotin, they all retained their explosive properties.

\section{CONCLUSIONS}

In conclusion, it was shown that by following simple procedures, $\mathrm{AgN}_{3}$ NPs can be embedded into a silica layer, which can be further derivatized with organic compounds of interest (biotin in our case). These hybrid nanoparticles can be used to study energetic nano-materials, with their explosion being trigged simply by heating.

\section{Acknowledgments}

This work was partially supported by a grant from the Romanian National Authority for Scientific Research, CNCS - UEFISCDI, project number PN-II-ID-PCE-20113-0408.

\section{REFERENCES}

1. Akhavan, J. The Chemistry of Explosives. Cambridge, UK, RSC, 2004.

2. Franzen, S., Lommel, S. A. Targeting Cancer with Smart Bombs: Equipping Plant Virus Nanoparticles for a Seek and Destroy Mission Nanomedicine 4 2004: pp. 575-588.

3. Zhou, F., Wu, S., Yuan, Y., Chen, W. R., Xing, D. Mitochondria-Targeting Photoacoustic Therapy Using Single-Walled Carbon Nanotubes Small 8 2012: pp. $1543-1550$.

4. Liu, L., Wang, W., Ju, X. J., Chu, L. Y. Smart ThermoTriggered Squirting Capsules for Nanoparticle Delivery Soft Matterials 6 2008: pp. 3759-3763.

5. Green, N. M. Avidin- the Nature of the Biotin-Binding Site Biochemical Journal 89 1963: pp. 599-609.

6. Korpela, J. Avidin, a High Affinity Biotin-Bindding Protein, as a Tool and Subject of Biological Research Medical Biology 62 1984: pp. 5- 26.

7. Grocholl, L., Wang, J., Gillan, E. G. Synthesis of SubMicron Silver and Silver Sulfide Particles via Solvothermal Silver Azide Decomposition Materials Research Bulletin 38 2003: pp. 213-220. http://dx.doi.org/10.1016/S0025-5408(02)01028-0

8. Jeon, C. S., Hwang, I., Chung, T. D. Virus-Tethered Magnetic Gold Microspheres with Biomimetic Architectures for Enhanced Immunoassays Advanced Functional Materials 23 2013: pp. 1484-1489.

9. Senevirathne, C., Pflum, M. K. H. Biotinylated Phosphoproteins from Kinase-Catalyzed Biotinylation Are 
Stable to Phosphatases: Implications for Phosphoproteomics ChemBioChem 14 2013: pp. 381-387.

10. Josten, A. E., Haalck, L., Spener, F., Meusel, M. J. Use of the Microbial Transglutaminase for the Enzymatic Biotinylation of Antibodies Journal of Immunology Methods 240 2000: pp. 47-54.

11. Johnson, N. J. J., Sangeetha, N. M., Boyer, J. C., Veggel, F. C. J. M. Facile Ligand-Exchange with Polyvinylpyrrolidone and Subsequent Silica Coating of Hydrophobic Upconverting $\quad \beta-\mathrm{NaYF}_{4}: \mathrm{Yb}^{3+} / \mathrm{Er}^{3+}$ Nanoparticles Nanoscale 2 2010: pp. 771-777.

12. An, Y. Q., Chen, M., Xue, Q. J., Liu, W. M. Preparation and Self-Assembly of Carboxylic Acid-Functionalized Silica Journal of Colloid and Interface Science 311 2007: pp. 507-513. http://dx.doi.org/10.1016/j.jcis.2007.02.084

13. Liu, Z. Z., Zou, S. H., Li, S., Liao, X. F., Hong, Y. J., Xiao, L. P., Fan, J. A General Synthesis of Mesoporous Metal Oxides with Well-Dispersed Metal Nanoparticles via a Versatile Sol-Gel Process Journal of Materials Chemistry A 1 2013: pp. 4038-4047. http://dx.doi.org/10.1039/c3ta00570d

14. Kim, J. H., Bryan, W. W., Lee, T. R. Preparation, Characterization, and Optical Properties of Gold, Silver, and Gold-Silver Alloy Nanoshells Having Silica Cores Langmuir 24 2007: pp. 11147-11152.
15. Herley, P. J., Jones, W. Electron-Microscopic Study of Ultra-Fine Particles of Silver Resulting from the ElectronBeam-Induced Decomposition of Silver Azide Journal of the Chemical Society Faraday Transactions 88 1992: pp. 3213-3216.

16. Ionita, G., Ghica, C., Turcu, I., Ionita, P. Reversible Aggregation between Nanoparticles Induced by Acid-Base Interactions Chemical Physics Letters 546 2012: pp. 133-135. http://dx.doi.org/10.1016/j.cplett.2012.08.009

17. Belokurov, G. M., Tupitsin, E. V., Aluker, D. E., Grechin, S. S., Nurmukhametov, D. R. Determining the Temperature of Silver Azide Explosion Products Technical Physics Letters 32 2006: pp. 23-24.

18. Aduev, B. P., Belokurov, G. M., Grechin, S. S., Tupitsin, E. V. Peculiarities of the Kinetics of Explosive Decomposition of Silver Azide Initiated by a Pulsed Electron Beam Technical Physics Letters 30 2004: pp. 774-775.

19. Zhu, W. H., Xiao, H. M. Ab Initio Molecular Dynamics Study of Temperature Effects on the Structure and Stability of Energetic Solid Silver Azide Journal of Physical Chemistry C 115 2011: pp. 20782-20787. 